\title{
Obituary
}

language had, nevertheless, an extraordinary faculty for quickly conveying his meaning to them and gaining their friendship.

To his widow we can offer only our sincerest sympathy and assure her that his friends will experience the loss of a distinguished and kindly colleague whose like they will never look upon again..

Herbert Tilley.

\section{WILLIAM SMITH KERR, M.B. Edin., F.R.C.S.E.}

WE regret to have to record the death of Mr William Smith Kerr, Surgeon in charge of the Ear and Throat Department of the Sheffield Royal Infirmary, which occurred at his home in Sheffield, quite unexpectedly, on 26 th November last, from pulmonary embolism. $\mathrm{He}$ was 59 years of age.

Mr Kerr was a native of Dumfries. He received his medical education at the University of Edinburgh, graduating M.B., C.M., in $r 890$. He came to Sheffield in $r 89 r$ to take up a resident post at the Sheffield Infirmary, and the rest of his life was passed in that city.

In 1904, the Infirmary instituted a special department for diseases of the ear and throat. Mr Kerr was at that time in general practice. His reputation with the board and staff of the institution was such that he was unanimously elected to the charge of the new department, and he thoroughly justified this signal mark of confidence. He enjoyed from the first the esteem of his colleagues, and he gradually established himself in the confidence of the profession and of the people of Sheffield and district. This was accorded to him in increasing measure up to the time of his death. He was remarkably modest and retiring in disposition. He owed his success to hard work, sound judgment and a genuine interest in the welfare of his patients.

The value of the department which he had built up at the Infirmary received public recognition when an entirely new block of buildings, fully equipped for the,work of the specialty, was opened at the Infirmary three years ago.

In spite of indifferent health, Mr Kerr served in France from the outbreak of the War, with the rank of Major, R.A.M.C., in command of a field ambulance.

For the last fifteen years he was frequently incapacitated by ill-health, but he laboured on under difficulties, and the amount of work he accomplished was phenomenal. Even during his illnesses, and when suffering severely, his solicitude for his hospital patients was unremitting, and he insisted on being kept informed of the progress of any special cases that might be causing anxiety. When recovering, it was difficult to induce him to remain away from his hospital work 


\section{Obituary}

sufficiently long to enable him to recruit. The immense concourse of medical men and people of all conditions who attended his funeral was a striking proof of the warm regard in which he was held by the medical profession of the district and by the numerous patients who had benefited by his skill. He leaves a widow and two sons, both of whom are grown to man's estate and occupying positions of responsibility.

G. Wilkinson.

\section{GREENFIELD SLUDER, M.D., F.A.C.S.}

ThE news of the death of Dr Greenfield Sluder of St Louis, at the age of $6_{3}$, was received with a genuine feeling of regret by his many friends in this country. For some months Dr Sluder's health had been considerably impaired as the result of septic poisoning which, in October last, necessitated amputation of one leg, an operation which was followed by fatal pneumonia.

Born in St Louis, he received his early training in his native city and graduated in medicine in 1888 at what was then the St Louis Medical College, but which is now the Washington University Medical School. After studying in Vienna he returned home, and a few years later gave his attention entirely to the subject of diseases of the nose and throat.

$\mathrm{His}$ reputation in the specialty, which one may justly characterise as world-wide, was gained by careful and concentrated study directed to the elucidation of certain types of headache and neuralgia of nasal origin, which he ascribed to irritation of the spheno-palatine ganglion and the nerve roots connected with it, due to disease in the neighbourhood; he also drew attention to the pain resulting from obstruction of the fronto-nasal duct-the so-called vacuum headache. Sluder's name has become associated with an operation for the enucleation of the tonsils by the guillotine and with a technique employed in the removal of nasal polypi. His monograph entitled "Nasal Neuralgia, Headaches and Eye Disorders," an amplification of his earlier work on the same subject, was recently reviewed at some length in this Journal.

As Clinical Professor and Director of the Department of Laryngology and Rhinology in the Washington University Medical School, he attracted a large number of men to his clinic for post-graduate instruction. Although his years of active and sustained application were approaching completion, his death leaves a distinct gap in the ranks of those engaged in the work of the specialty. Greenfield Sluder has bequeathed to his successors much useful, original work, and his perseverance in the field of research should serve as a fine example for others to follow.

A. Logan TURner. 